\title{
Modelling and back-analysing failures in steep limestone cliffs M. Frayssines ${ }^{(1)}$, D. Hantz ${ }^{(2)}$
}

\author{
(1) EGIS SE - Geotechnique, Seyssins, France \\ (2) LGIT, Université Joseph Fourier Grenoble, CNRS, Observatoire de \\ Grenoble, France \\ Corresponding author: D. Hantz (Didier.Hantz@ujf-grenoble.fr)
}

March 2009

\begin{abstract}
The observation of 12 rock fall scars in steep limestone cliffs has shown that the fallen masses were stable as a result of relatively small rock bridges. These results demonstrate that consideration of rock bridges is necessary for a realistic evaluation of stability. Limit equilibrium methods of analysis are presented for sliding and toppling, for both isostatic and hyperstatic conditions. These methods are illustrated with four case histories. The results of 9 back-analyses of rock falls with volumes between $24 \mathrm{~m}^{3}$ and $3500 \mathrm{~m}^{3}$ are presented. The rock cohesion obtained from back-analysis appears to be significantly lower than the cohesion obtained from classical laboratory tests. This discrepancy can be attributed to several factors including: a spatial and temporal scale effect, the oversimplified modelling (two-dimensional limit equilibrium) and some uncertainties affecting the geometrical data. When analysing the stability of a cliff with a limit equilibrium method, the authors suggest dividing the cohesion by a "scale and method" factor of 3 .

Keywords: Rock bridge, back-analysis, toppling, sliding, limestone cliff.

\section{Introduction}

Anaclinal slopes in hard sedimentary rocks can be very steep and can have large overhangs, which can be natural or due to the construction of mountain roads. Rock falls in these steep cliffs are due to either slide or topple. A survey of 25 rock falls that have occurred in the French Subalpine ranges, with volume from $20 \mathrm{~m}^{3}$ to $30,000 \mathrm{~m}^{3}$ [1], has made it possible to identify typical failure configurations for these anaclinal slopes (Fig. 1).

Figure 1 shows 3 typical failure configurations observed between the surveyed 25 rock fall events. Where the beds dip less than $30^{\circ}, \mathrm{A}$ and $\mathrm{B}$ failure configurations have been observed. In the first one (A), the unstable rock mass rests on a steep joint plane, which is roughly perpendicular to the bedding (cross-joint), on which sliding is possible in a translational mode. Toppling is also possible depending on the size of the overhang. In the second configuration (B), the cross-joint is not sufficient to constitute a failure surface and another joint (less inclined and generally shorter than cross-joints) makes up the low bound of the unstable block, on which sliding is possible. Sliding may occur on this singular joint in a translational mode (with opening of the cross-joint) or in a more complex mode (compound slide). Toppling requires opening of both joints. Where the beds dip more than
\end{abstract}


$30^{\circ}$ opposite the slope, the $\mathrm{C}$ configuration has been observed. The main joint set is perpendicular to the bedding and it defines a potential sliding surface. This failure surface is stepped where the bedding planes form overhangs. For the two first configurations, it is often difficult to know which of the two mechanisms will occur: sliding or toppling, if no precise cliff topographical model is available. In this case, both sliding and toppling must be considered in the analysis.

Twelve failure surfaces were closely observed (generally using rappelling): in these latter fresh intact rock fracture surfaces were visible, representing a small percentage of the whole failure surface (0.2 to 5\%). In the case of toppling failures, these surfaces are due to fracturing of the rock bridges which had kept the rock mass in equilibrium for several decades. In the case of sliding they may also be due to fracturing of prominent bumps on the sliding surface.

Stability analyses of the configurations described above are necessary for a better assessment of rock fall hazard, which is usually qualitative [2], and for mitigation studies (bolting, mining). As the size and location of the rock bridges inside the rock mass are hardly accessible to observation, these are usually neglected. This is acceptable in rock slope design because it leads to a conservative design $[3,4]$. Should the rock bridges be neglected in hazard assessment, the analysis would conclude that cliffs which have existed for several centuries have very low safety factors. A realistic hazard assessment needs to consider the rock bridges which exist on the potential failure surfaces. Methods for stability analysis of potential translational rock slides (planar slides and stepped slides) have been proposed $[5,6,7,8,9]$. The methods were applied to a priori analyses of potential rock slides, but they were not validated by back-analyses of actual rock slides. Paronuzzi and Serafini [10] back-analysed rock slides and topples involving rock bridge failure to determine the intact rock cohesion and tensile strength. However, they did not compare the values obtained to laboratory test results.

Stability analyses with rock bridges need to know their strength parameters. Classical laboratory tests on intact rock specimens can be used, but the scale effect can be high and does not work on the side of safety. The authors undertook back analyses of cliff failures to determine the in situ rock bridge strength [11]. The methods used for both sliding and toppling analyses are described in this paper. Since the static conditions may be isostatic or hyperstatic, two different methods have been applied for both sliding and toppling. These are presented with four case studies; in addition the results of nine back-analyses are given and discussed.

\section{Morphological and geological setting}

The 25 rock falls which were surveyed to identify typical failure configurations occurred in the French Subalpine Ranges, which represent part of the sedimentary cover of the External Crystalline Massifs of the French Alps, and belong to the Dauphinoise (or Helvetic) zone (Fig. 2). The front ranges are made of limestone and marls of the upper Jurassic and Cretaceous. Typically, valley walls consist of a succession of steep calcareous cliffs and marly slopes. The calcareous cliffs belong to Tithonian, Valanginian, Barremian (Urgonian facies), and Campanian-Maastrichtian stages. The highest cliffs are up to 450m high. The back-analyzed rock falls occurred in Urgonian limestone cliffs.

\section{Survey methodology}


The rock falls have been easily identified thanks to the bright scar they left (in contrast with the patina of the cliff), and the damage they produced in the forest. The scars have been surveyed, roping down in the cliff, in order to collect geometrical and structural information: dimensions of the scar, of the intact rock fractures, discontinuities making up the failure surface (orientation, extension, roughness, cover). This information is given in a previous paper [1]. Intact rock fracturing is indicated by the colour of fresh intact rock, which is light beige to light rosy for Urgonian limestone. Fresh fracture surfaces usually contrast with the rest of the scar, which is often coated with a calcite crust, whose colour may vary from white to orange, according to the quantity of iron oxide in the calcite. These surfaces usually represent a very small part of the scar area (usually less than $1 \%$ ). They may result from fracturing of rock bridges, or bumps in the case of sliding planes. Bumps fracturing may be caused by either the initial failure or the subsequent friction of the moving mass. Slip evidences are rarely observed on very steep sliding planes (A configuration in Fig.1), probably because the normal forces are to low in these cases. In the absence of slip evidences, the observation of fracture surfaces doesn't allow distinguishing a shear from a tensile failure. So the failure mechanism is usually derived from the reconstruction of the original cliff surface.

\section{Mechanical characterisation}

Porosity and density measurements, uniaxial and triaxial compression tests, and Brasilian tests were carried out in the laboratory, on Urgonian limestone in order to evaluate the intact rock's physical and mechanical parameters [11] (Table 1). The friction angle and cohesion values for the intact rock were derived from triaxial compression tests, using the Coulomb failure criterion. However, this criterion would give an overestimated strength in the field of normal tensile stresses [12]. Instead, a bilinear criterion is assumed, which defines a "tensile friction angle" as the slope of the failure criterion for tensile normal stresses (Fig. 3). Our test results give a ratio of cohesion to tensile strength equal to 3.3. Hoek [13] has shown that a rock is characterized by the shape of the intact rock failure criterion, which is not affected by the scattering of the rock strength from one sample to another. It means that the cohesion and the tensile strength are not independent and the uncertainty affecting the tensile friction angle is much smaller than those affecting these parameters.

Mechanical characteristics of Urgonian limestone joints have been determined from direct shear tests on $0.40 \mathrm{~m}$ x $0.25 \mathrm{~m}$ specimens [14] (Table 1). These tests produced peak friction angles between 30 and $43^{\circ}$. However the roughness observed at the scale of the scar $\left(>10 \mathrm{~m}^{2}\right)$ is higher than that of the samples due to large scale steep ondulations. It ensues that the scale effect could be either positive or negative (according to [15]), although an identical roughness at both scales would lead to a lower friction angle at the larger scale [16]. A negative scale effect was observed by Locher et al. [17], who obtained an in situ peak friction angle $5^{\circ}$ higher than that measured in the laboratory on smooth limestone joint samples.

\section{Back analyses}

Back analyses of toppling and sliding were carried out in two dimensions using the limit equilibrium method. As the analysed rock falls were not linked to any noticeable seismic or 
hydrological event, the only acting force which was considered was the weight of the falling mass. All forces acting on the rock mass were assumed to be in a vertical plane containing its centre of gravity, parallel to the displacement vectors. This implies that the centres of the rock bridges belong to this plane. So the only moments which were considered are perpendicular to this plane. Otherwise, moments belonging to this plane should be considered and a mode III fracture (referring to fracture mechanics theory, [18]) could occur.

Zero tensile strength and cohesion values were assumed for discontinuities and the bridges were assumed to have the properties of intact rock. We considered that their friction angle was less affected by the scale effect than their cohesion, and then we took the value of $54^{\circ}$ given by the laboratory tests (Table 1 ). Based on our in situ observations of the joint roughness, the most relevant value for the friction angle of the discontinuities is $43^{\circ}$.

\subsection{Sliding}

\subsubsection{Isostatic model}

Figure 4 shows the method of analysis applied for the isostatic condition modelling. The resisting force required for equilibrium, is determined by the equilibrium equations. Different values for the mechanical parameters of the rock bridges and the joints can give this resisting force. We considered that the friction angles were given by the laboratory tests and we determined the rock bridge cohesion which gave the required resisting force. By using the limit equilibrium method in the $X$ and $Y$ directions, equations 1 and 2 are obtained:

On the $X$ axis : $N=W \cos \alpha$

On the $Y$ axis : $T=W \sin \alpha$

Where $W$ is the weight of the unstable rock mass, $N$ and $T$ are normal and tangential components of the resisting force and $\alpha$ is the dip of the sliding plane.Assuming that the normal stress is uniformly distributed on the sliding plane and that this plane has no cohesion outside the rock bridges, the tangential resisting force is:

$$
\left.T=N \backslash 1-a_{r b}\right) \tan \phi_{d}+a_{r b} \tan \phi_{r b} \stackrel{-}{+} c_{r b} A_{r b}
$$

Where $\phi_{d}$ is the friction angle of the sliding plane, $a_{r b}$ is the surface proportion of intact rock bridges on the sliding plane, $c_{r b}$ and $\phi_{r b}$ are the cohesion and friction angle of the rock bridges and $A_{r b}$ is the total area of the rock bridges.

The in situ cohesion of the rock bridge, which explains the failures observed, is obtained using Eq. (1) to (3):

$$
c_{r b}=\frac{W\left\lfloor\operatorname{in} \alpha-\cos \alpha \Lambda-a_{r b} \tan _{d}+a_{r b} \tan \phi_{r b} \longleftarrow\right.}{A_{r b}}
$$

\section{Case history}

The Pas du Fouillet rock fall occurred on July 1998 in the South-West part of the Vercors massif (Fig. 2), involving a volume of $24 \mathrm{~m}^{3}$. The failure is located in the middle 
part of a $200 \mathrm{~m}$ high urgonian limestone cliff striking $\mathrm{N} 10^{\circ}$ and dipping $85^{\circ}$ to the West. Two major joint sets $\mathrm{N} 10^{\circ} / 81^{\circ} \mathrm{W}(\mathrm{J} 1)$ and $\mathrm{N} 114^{\circ} / 81^{\circ} \mathrm{SW}(\mathrm{J} 2)$ cut sub-horizontal limestone beds. The sliding plane is about $10 \mathrm{~m}$ high and $4 \mathrm{~m}$ wide and it is made up of a joint N0$5^{\circ} / 80^{\circ} \mathrm{W}$ belonging to the $\mathrm{J} 1 \mathrm{set}$ (Fig. 5). It is bounded to the North by a joint $\mathrm{N} 110^{\circ} / 90^{\circ}$ belonging to the $\mathrm{J} 2$ set, which opened when sliding occurred. A fresh fracture surface with an area of $0.08 \mathrm{~m}^{2}$ is due to a rock bridge fracture (Fig. 5B). The cohesion of the rock bridge as determined by back analysis is $6.6 \mathrm{MPa}$.

\subsubsection{Hyperstatic model}

Hyperstatic sliding occurs when resisting forces act not only on the sliding plane, but also on the rear opening plane. This case occurs when rock bridges exist in the rear opening plane.

Figure 6 shows the method of analysis applied for the hyperstatic conditions modelling. By using the limit equilibrium method in the $X$ and $Y$ directions, equations 5 and 6 are obtained:

On the $X$ axis : $N_{l}=W \cos \alpha+R_{2} \cos (\delta+\beta-\alpha)$

On the $Y$ axis $: T_{1}=W \sin \alpha-R_{2} \sin (\delta+\beta-\alpha)$

Where $N_{l}, T_{1}$ are the normal and tangential components of the resisting force on the sliding plane, $R_{2}$ is the resisting force on the opening plane (with $N_{2}$ and $T_{2}$ its normal and tangential components), $\alpha$ and $\beta$ are the dips of the sliding plane and the opening plane, and $\delta$ is the angle between $R_{2}$ and $N_{2}$.

The normal and tangential components $N_{2}$ and $T_{2}$ are:

$N_{2}=-R_{2} \cos \delta$

$T_{2}=R_{2} \sin \delta$

The sliding plane undergoes a compression $\left(N_{l}\right.$ is positive) and the failure criterion is:

$T_{1}=N_{1}\left(1-a_{r b}\right) \tan \phi_{d}+a_{r b} \tan \phi_{r b} \stackrel{-}{+} c_{r b} A_{r b l}$

Where $A_{r b 1}$ is the total area of the rock bridges on the sliding plane.

The opening plane undergoes a tension $\left(N_{2}\right.$ is negative $)$ and the failure criterion is:

$T_{2}=N_{2} \tan \psi+c_{r b} A_{r b 2}$

Where $A_{r b 2}$ is the total area of the rock bridges on the plane 2 and $\tan \psi$ is the ratio between the cohesion and the tensile strength of the rock bridge (Fig. 3).

Introducing Eq. (7) and (8) in Eq. (10), the failure criterion becomes:

$$
R_{2}=\frac{c_{r b} A_{r b 2}}{\sin \delta+\cos \delta \cdot \tan \psi}
$$


Contrary to the isostatic case, the resisting forces required to ensure equilibrium are not determined by the equations of equilibrium and the rock bridge cohesion cannot be determined without an additional assumption. Indeed, the equilibrium Eq. (5) and (6), and the failure criteria Eq. (9) and (11), give 4 equations and the number of unknowns is $5\left(N_{l}\right.$, $\left.T_{1}, R_{2}, \delta, c_{r b}\right)$. Following Panet and Rotheval [19], we make the additional assumption that the resisting force $R_{2}$ is parallel to the direction of sliding. Then, the angle $\delta$ is known and the problem can be solved. The in situ cohesion of the rock bridge, which explains the observed failure, is given by the expression:

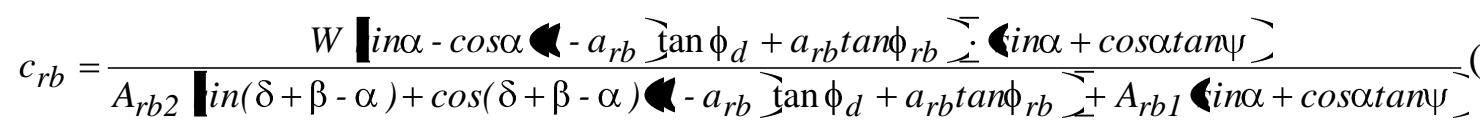

\section{Case history}

The Dent du Loup rock fall, with a volume of $6000 \mathrm{~m}^{3}$, occurred during the night of 4th January 2001, in the Vercors massif, $8 \mathrm{~km}$ North-West of the town of Grenoble (Fig. 2). The major part of the fragmented rock mass stopped near the toe of the cliff, destroying 0.5 $\mathrm{hm}^{2}$ of wood. One block stopped $150 \mathrm{~m}$ from houses located in the valley. The rock fall broke away from the top of a $180 \mathrm{~m}$ high limestone cliff striking $\mathrm{N} 50^{\circ}$ and dipping $85-90^{\circ}$ to the north-west. The scar is roughly $60 \mathrm{~m}$ high and $15 \mathrm{~m}$ wide. From analysis of aerial photographs, four main subvertical joint sets were detected: $\mathrm{N}^{\circ}(\mathrm{J} 1), \mathrm{N} 50-70^{\circ}(\mathrm{J} 2), \mathrm{N} 80-$ $100^{\circ}(\mathrm{J} 3)$ and $\mathrm{N} 140-160^{\circ}(\mathrm{J} 4)$. In the scar, bedding planes $\left(\mathrm{N} 0^{\circ} / 30^{\circ} \mathrm{E}\right)$ form several overhangs (Fig. 7A). The failure surface is made up of bedding planes, a main irregular sliding surface $\mathrm{N} 60 / 70-85^{\circ} \mathrm{NW}$ which belongs to joint set $(\mathrm{J} 2)$ and two lateral planes in the upper part of the scar: $\mathrm{N} 145^{\circ} / 75^{\circ} \mathrm{SW}$ (on the North-East side) and N145/90 (on the SouthWest side), belonging to the joint set (J4) (Fig. 7B). The main sliding surface can be approximated by two planes: a lower plane (1) dipping $70^{\circ}$ and an upper plane (2) dipping $75^{\circ}$ (Fig. 7). According to the block theory [20], the failure mechanism was a wedge slide on the two planes $\mathrm{N} 60 / 70^{\circ} \mathrm{NW}$ and $\mathrm{N} 145^{\circ} / 75^{\circ} \mathrm{SW}$. However, the normal stress was mainly applied on the plane $\mathrm{N} 60 / 70^{\circ} \mathrm{NW}$ and there was no cohesion on the lateral plane $\mathrm{N} 145^{\circ} / 75^{\circ} \mathrm{SW}$ (no fresh fracture). Thus the resisting force on the lateral plane was neglected and a planar slide was assumed on the plane N60/70NW. Fresh fracture surfaces cover $4.7 \mathrm{~m}^{2}$ on the plane 1 and $4.3 \mathrm{~m}^{2}$ on the plane 2 . The total scar area was $1000 \mathrm{~m}^{2}$. The cohesion of the rock bridges determined by back analysis was $12.4 \mathrm{MPa}$.

\subsection{Toppling}

\subsubsection{Isostatic model}

In the observed cases of isostatic toppling, the rock bridges were concentrated in the lower part of the scar. In the model the zone where the rock bridges are concentrated, was considered as a unique equivalent rock bridge, with equivalent strength properties (Fig. 8B).

Figure 8A shows the equilibrium conditions of forces and moments described by equations (13 15):

On the $X$ axis : $N=W \sin \alpha$ 
On the $Y$ axis : $T=W \cos \alpha$

On the $Z$ axis : $M_{f z}=W d$

Where $N$ and $T$ are the normal and tangential components of the resisting force on the rock bridge, $M_{f z}$ is the resisting moment on the $Z$ axis, due to the rock bridge, $\alpha$ is the angle between the rock bridge plane ( $Y$ axis) and a vertical line, and $d$ is the moment arm of the weight $W$ of the unstable rock mass.In limit equilibrium sliding analysis, stresses are usually considered to be constant along the sliding planes [3]. In toppling analysis, it can be seen in Figure 8A that the force equilibrium needs the total normal resisting force to be compressive, but the moment equilibrium implies that tension exists in the upper part of the rock bridge. It ensues a non-constant normal stress distribution in the rock bridge. As in structural engineering, a linear distribution of the normal stress along the rock bridge is assumed (Fig. 9A). The difference between the minimal (tensile) normal stress $\left(\sigma_{\min }\right)$ and the mean (compressive) normal stress $(\bar{\sigma})$ is:

$$
\bar{\sigma}-\sigma_{\min }=\frac{6 M_{f z}}{H_{r b}^{2} \cdot l_{f}}
$$

Where $H_{r b}$ is the height of the equivalent rock bridge (Fig. 8) and $l_{f}$ is the width of the failure surface (Fig. 8).

The mean normal and shear stresses $\bar{\sigma}$ and $\tau$ are given by:

$$
\begin{gathered}
\bar{\sigma}=\frac{N}{H_{r b} \cdot l_{f}} \\
\tau=\frac{T}{H_{r b} \cdot l_{f}}
\end{gathered}
$$

The shear stress is assumed to be constant along the fracture plane. From Eq. (13), (15), (16) and (17), the minimal normal stress in the rock bridge, which explains the observed failure, is given by:

$$
\sigma_{\min }=\frac{W \boldsymbol{H}_{r b} \sin \alpha-6 d^{-}}{H_{r b}^{2} \cdot l_{f}}
$$

Note that for design purposes, the hypothesis of a linear distribution of the normal stress (Fig. 9A) is more conservative (or more pessimistic) than the hypothesis of a rectangular distribution (Fig. 9B), which is adopted, for example, in the UDEC code [21]. For the second hypothesis the calculation would lead to the following Eq. (20): 
$\sigma_{\text {min }}=\frac{W \boldsymbol{H}_{r b^{\sin \alpha}-2 d^{-}}}{H_{r b}^{2} \cdot l_{f}}$

The above calculated stresses correspond to equivalent (or apparent) stresses acting on an equivalent rock bridge. Assuming that the total width of the rock bridge is constant on the height of the equivalent rock bridge, the actual stresses $\sigma$ are proportional to the equivalent stresses $\sigma^{\prime}$ and they are given by:

$$
\sigma A_{r b}=\sigma^{\prime} A^{\prime}{ }_{r b}
$$

Where $A_{r b}$ is the total area of the actual rock bridges (Fig. 8B) and $\mathrm{A}_{\mathrm{rb}}$ ' is the area of the equivalent rock bridge (Fig. $8 \mathrm{~B}$ ).

At failure, the normal and shear stresses meet the failure criterion of the rock. From the values of the critical normal and shear stresses (Eq. (18) and (19)), which occur at the upper tip of the rock bridge, the in situ tensile strength and cohesion can be estimated.

\section{Case history}

The Ranc rock fall occurred on 30th January, 2004, $50 \mathrm{Km} \mathrm{SW}$ of Grenoble (Fig. 2). $2200 \mathrm{~m}^{3}$ of rock collapsed onto the road, killing two people in a car. The cliff is $150 \mathrm{~m}$ in height, strikes N80 and dips $85-90^{\circ}$ to the South. The fall occurred where the cliff formed an overhang due to the construction of the road 150 years ago (Fig. 10B). The limestone beds strike $\mathrm{N}^{\circ}$, dip $15^{\circ}$ to the East, and they are cut perpendicularly by 2 joint sets $\mathrm{N} 100^{\circ} / 90^{\circ}(\mathrm{J} 1)$ and $\mathrm{N} 33^{\circ} / 75^{\circ} \mathrm{SE}(\mathrm{J} 2)$. The scar is $50 \mathrm{~m}$ wide, about $20 \mathrm{~m}$ high and the mean thickness of the fallen mass was approximately $2.5 \mathrm{~m}$. The failure surface is made up of a bedding plane $\mathrm{N} 0 \% / 15^{\circ} \mathrm{E}$ and two planes, $\mathrm{N} 90 / 80-85^{\circ} \mathrm{S}$ and $\mathrm{N} 40^{\circ} / 85^{\circ} \mathrm{NW}$ belonging respectively to the joint sets (J1) and (J2) (Fig. 10A). In the major part of the scar, the rock is coated by a calcite crust (yellowish-orange colour). Intact rock fracture surfaces have been observed in the lower part of the plane $\mathrm{N} 90^{\circ} / 80-85^{\circ} \mathrm{S}$ (Fig. 10). These fresh fracture surfaces, which cover an estimated area of $52 \mathrm{~m}^{2}$ (5\% of the whole scar area), are due to the failure of rock bridges. The equivalent rock bridge considered in the analysis has a height of $3.5 \mathrm{~m}$ and a width of $35 \mathrm{~m}$. We obtained tensile strength and cohesion values equal to 3.2 $\mathrm{MPa}$ and $10.5 \mathrm{MPa}$ respectively.

\subsubsection{Hyperstatic model}

Figure 11 shows the equilibrium conditions of forces and moments described by equations $(22-24)$ :

On the $X$ axis : $T_{1}-R_{2} \cos (\delta+\pi / 2-\beta)=0$

On the $Y$ axis : $N_{1}-R_{2} \sin (\delta+\pi / 2-\beta)-W=0$

On the $Z$ axis : $R_{2} d_{2}-W d_{1}=0$

Where $N_{1}$ and $T_{1}$ are the normal and tangential components of the resisting force $R_{1}$ on the point $O, R_{2}$ is the resisting force on the rock bridge $\left(N_{2}\right.$ and $T_{2}$ : normal and tangential 
components), $d_{1}$ is the moment arm of the weight $W, d_{2}$ is the moment arm of $R_{2}, \delta$ is the angle between $R_{2}$ and the normal to the rock bridge surface and $\beta$ is the angle between the rock bridge surface and a horizontal plane.

The failure criterion for the rock bridge is given by equation (9) and shown in Figure 3. This hyperstatic problem has 5 unknowns $\left(N_{l}, T_{1}, R_{2}, \delta, C_{r b}\right)$ and 4 equations (Eq. 22 to 25). The angle $\delta$ was determined using the maximum work principle in order to calculate the resisting force in a rock bolt [22]. This principle is illustrated in Fig. 12. In a normal versus shear force diagram, the end of the resisting force $R_{2}$ on rock bridge, must be located on the failure criterion, in such a way that the scalar product of the displacement vector $\vec{u}$ and the opposite of force $R_{2}$ is maximum (the opposite of $R_{2}$ is the force exerted by the moving mass, on the stable rock mass). Introducing Eq. (26) and (27) into Eq. (25), the cohesion of the rock bridge is:

$c_{r b}=\frac{R_{2}(\sin \delta+\cos \delta \tan \psi}{A_{r b}}$

Note that the verification of the shear failure criterion on point 0 (Eq. (29)) is needed for the validation of the cohesion obtained.

$T_{1} \leq N_{1} \tan \phi_{1}$

If this criterion is not fulfilled, then $T_{1}=N_{1} \tan \phi_{1}$ is imposed.

\section{Case history}

The Goule Blanche rock fall, with a volume of about $30 \mathrm{~m}^{3}$, occurred in the upper part of a $200 \mathrm{~m}$ high cliff, striking $\mathrm{N} 30^{\circ}$, at an unknown date around the year 2000 . Beds are horizontal and cut by two steeply dipping joint sets which strike $\mathrm{N} 64^{\circ}$ (J1) and $\mathrm{N} 152^{\circ}$ (J2). The failure surface is about $7 \mathrm{~m}$ high. It is made up first by a wedge defined by two surfaces $\mathrm{N} 65^{\circ} / 80-90^{\circ} \mathrm{SE}$ and $\mathrm{N} 150^{\circ} / 85-90^{\circ} \mathrm{SW}$ belonging respectively to sets $\mathrm{J} 1$ and $\mathrm{J} 2$ (Fig. 13A). These two surfaces are coated with a calcite crust. In the lower part of this wedge, there is a singular plane $\mathrm{N} 30^{\circ} / 75^{\circ} \mathrm{NW}$, which includes a fresh intact rock fracture surface (Fig. 13B). This fracture surface has an area of $0.2 \mathrm{~m}^{2}(0.8 \%$ of the scar area). The base of the block is made up of a horizontal bedding plane. The lower part of the fallen mass was overhanging, allowing for a toppling mechanism (Fig. 13C). According to the maximum work principle, the stress in the rock bridge was a pure shear stress (Fig. 12). With a friction angle of $30^{\circ}$ for the base of the block, the failure criterion (Eq. 9) is fulfilled. The estimated in situ cohesion and tensile strength values are respectively $14 \mathrm{MPa}$ and 4.2 $\mathrm{MPa}$.

\subsection{Other analyses}

Five other cases have been back-analysed using the methods described above [11]. The mechanical parameters obtained for all cases are given in Table 6.

\section{Discussion}

\subsection{Importance of rock bridges}


The back-analyses of nine rock falls have shown that the compartments had been stable for a long time thanks to rock bridges and that the proportion of rock bridges in the failure surfaces was very small. It means that compartments with the same geometrical configuration but with a significantly higher proportion of rock bridges are very stable. It ensues that classical stability analyses, which does not usually take rock bridges into account, often lead to pessimistic results and to unnecessary mitigation measures. It is therefore very important to develop geophysical methods to investigate rock bridges, and convincing results have been obtained with ground penetrating radar [23,24,25].

\subsection{Back analysis and laboratory mechanical parameters}

It can be seen in Table 2 that the rock bridge cohesion obtained from back analysis is always lower ( 2 to 9 times lower) than the average cohesion obtained from laboratory tests. This discrepancy could be due to the natural dispersion of the rock strength, but in that case, it would not be always in the same way. It may be due to scale effects or to an oversimplified modelling (these two points are developed hereafter), but also to uncertainties affecting the data used for modelling. These uncertainties mainly concern the pre-failure cliff morphology and the rock bridge fracture area. The pre-failure cliff morphology is well known when a pre-failure, digital elevation model (DEM) or photographs were available. In these cases (Dent du Loup and Ranc rock falls), a postfailure DEM was achieved and the exact shape of the fallen compartment could be determined. In the other cases, the pre-failure cliff morphology was reconstructed by extrapolating the adjacent cliff surfaces. In these cases, prominent overhangs could have been omitted, leading to an underestimation of the rock bridge strength. In sliding cases, some fresh fracture areas could be due to bump fracturing, occurring after the initial failure, and due to sliding of the rock mass. Taking into account such fracture areas leads also to underestimate the rock bridge strength. Note that the three lowest values in Table 6 could be affected by both types of error. Moreover, the lowest value corresponds to the case where the uncertainty affecting the pre-failure morphology appears to be the most important. On the other hand, the cohesion values obtained using the exact shape of the rock compartments (Dent du Loup and Ranc rock falls) are greater than $10 \mathrm{MPa}$. From these considerations, it appears that the rock bridge cohesion obtained from back analysis is 2-3 times lower than the average cohesion obtained from laboratory tests. The authors propose that the cohesion obtained from classical laboratory tests must be divided by this "scale and method" factor, when evaluating the stability of a cliff.

\subsection{Spatial and temporal scale effects}

The size of the rock bridge fracture surfaces is one to two orders of magnitude greater than that of the tested specimen. The spatial scale effect has been analysed for limestone by Bieniawski and Van Heerden [26]. For specimens sized between $10 \mathrm{~cm}$ and 1 metre, the cohesion is divided by 3 . The temporal scale effect is due to the fact that a more or less constant stress had been applied for a long time (at least several tens of years) in rock bridges, whereas in the laboratory, the stress increases in some minutes from zero to the instantaneous strength. Creep tests on limestone have shown that the long term strength can be 0.61 to 0.78 times the instantaneous strength for tests lasting only several days $[12,27]$. Lower values can be expected for loading lasting several decades. These results can not be 
directly applied to the analyzed cases because they have been obtained from different limestones and from uniaxial compression tests, in which the stress state is quite different from that acting in the analyzed rock bridges (uniaxial tension or quasi-pure shear). However they yield a semi-quantitative explanation of our results.

\subsection{Oversimplified modelling}

The limit equilibrium method assumes that the strengths of the different parts of the failure surface are mobilised simultaneously. The method does not take into consideration that the rock bridges probably have a higher stiffness than that of the joints and thus undergo higher stresses than those assumed in the model. In the case of sliding, this leads to an underestimation of the rock bridge cohesion. Stress-strain modelling should be used to overcome this drawback. It would also give more realistic results for hyperstatic mechanisms. Moreover, shear or tensile stress concentrations at the joint tips have not been considered. This also leads to an underestimation of the rock bridge cohesion or tensile strength. Fracture mechanics methods should be used to take this phenomenon into account $[8,28,29]$. Also, the use of a two-dimensional model does not make it possible to simulate the possible torsion of rock bridges, which can lead to a mode III rupture. This also underestimates the rock bridge cohesion.In engineering practice, the authors suggest that the proposed method could be used as a preliminary tool to determine what cases need a more sophisticated modelling. For example, when the stability is ensured while applying a large reduction factor, more precise modelling is not necessary. In the context of natural hazard assessment, the proposed modelling appears to be sufficient to assess the present state of stability of potentially unstable rock compartments, accounting for the uncertainty affecting the prediction of their future behaviour.

\section{Conclusion}

The observation of 12 rock fall scars has shown that the fallen masses had been stable due to relatively small rock bridges. It ensues that taking into account rock bridges is necessary for realistic stability evaluation. However, 9 back analyses with limit equilibrium methods have shown that the rock cohesion obtained from classical laboratory tests must be divided by 2 or 3 to explain the observed failures. This discrepancy is due largely to two factors: a spatial and temporal scale effect and the oversimplified modelling (two-dimensional limit equilibrium).However, the authors propose using the limit equilibrium method as a preliminary tool in engineering practice and suggest dividing the cohesion by a "scale and method" factor of 2 or 3. Where a mode III rupture [18] is possible, a three-dimensional analysis appears to be necessary. The authors consider that using fracture mechanics methods could improve modelling of rock bridge fracture. Finally, the development of geophysical methods to investigate the continuity (and the rock bridges) of potential failure surfaces is encouraged.

\section{Acknowledgement}

The authors would like to thank the "Pôle Grenoblois Risques Naturels" and the "Région Rhône-Alpes" for their funding. 


\section{References}

[1] Frayssines M, Hantz D. Failure mechanisms in calcareous cliffs of the Subalpine range (French Alps). Engineering Geology 2006;86(4):256-270.

[2] Hantz D, Vengeon JM, Dussauge-Peisser C. An historical, geomechanical and probabilistic approach to rock-fall hazard assessment. Natural Hazards and Earth System Sciences 2003;3:693-701.

[3] Hoek E, Bray JW. Rock Slope Engineering. London: The Institution of Mining and Metallurgy, 1981.

[4] Hantz D. Ingénierie des pentes rocheuses naturelles et artificielles. Les Techniques de l'Industrie Minérale 2001;10:66-75.

[5] Call RD, Nicholas DE. Prediction of step path failure geometry for slope stability analysis. In: Proc $19^{\text {th }}$ US Symp on Rock Mechanics, Reno, 1978.

[6] Einstein HH, Veneziano D, Baecher GB, O'Reilly KJ. The effect of discontinuiuty persistance on rock slope stability. Int J Rock Mech Min Sci \& Geomech Abstr 1983;20 (5):227-236.

[7] Glynn EF, Veneziano D, Einstein HH. The probabilistic model for shearing resistance of jointed rock. In: Proc $19^{\text {th }}$ US Symp on Rock Mechanics, Reno, 1978.

[8] Kemeny J. The time dependent reduction of sliding cohesion due to rock bridges along discontinuities: a fracture mechanics approach. Rock Mechanics and Rock Engineering 2003;36:27-38.

[9] Scavia C, Saetta V. Metodo meccanico-probabilistico per l'analisi della stabilità dei pendii in roccia. In: Prevenzione dei fenomeni di instabilità delle pareti rocciose, Programma Interreg IIC, Carere K, Rato S, Zanolini F, ed. 2001, pp 116-132.

[10] Paronuzzi P, Serafini W. The influence of rock bridges in block fall processes. Italian Journal of Engineering Geology and Environment 2005;1:37-55.

[11] Frayssines M. Contribution à l'évaluation de l'aléa éboulement rocheux (rupture). Thesis, Université Joseph Fourier, Grenoble, 2005.

[12] Goodman RE. Introduction to Rock Mechanics. New York: Wiley, 2004.

[13] Hoek E. Strength of jointed rock masses. Géotechnique 1983;33: 187-223.

[14] Ramirez-Rascon A. Analyse géotechnique des glissements de versants sédimentaires sur des plans de stratification. Thesis, Université Joseph Fourier, Grenoble, 1984. 
[15] Bandis S, Lumsden AC, Barton NR. Experimental studies of scale effects on the shear behaviour of rock joints. Int J Rock Mech Min Sci 1981;18:1-21.

[16] Barton NR, Bandis S. Effects of block size on the shear behaviour of jointed rock. In: $23^{\text {rd }}$ US symp on rock mechanics. Berkeley, 1982, pp 739-760.

[17] Locher HG, Rieder UG. Shear tests on layered Jurassic limestone. In: Proc 2nd Congr Int Soc for Rock Mechanics, Belgrade, vol. 2. 1970, paper 3-1.

[18] Atkinson BK. Introduction to fracture mechanics and its geophysical applications. In: Fracture Mechanics of Rocks, BK Atkinson, ed. London: Academic Press, 1991, pp 1-26.

[19] Panet M, Rotheval JP. Stabilité des masses rocheuses. In: La mécanique des roches appliquée aux ouvrages de génie civil. Paris, AAIAEENPC, 1976, pp 109-119.

[20] Goodman RE, Shi GH. Block Theory and its Application to Rock Engineering. London: Prentice-Hall, 1985.

[21] Itasca. Universal distinct element code (UDEC) version 3.10. Itasca consulting group, Inc. Minneapolis, USA, 1999.

[22] Panet M. Renforcement des fondations et des talus à l'aide d'ancrages actifs et passifs. In: Proc. 6th Int Congr Rock Mech, Montreal, Vol.3. 1987, pp 1569-1578.

[23] Dussauge-Peisser C, Wathelet M, Jongmans D, Hantz D, Couturier B, Sintes M. Investigation of a fractured limestone cliff (Chartreuse Massif, France) using seismic tomography and ground penetrating radar. Near Surface Geophysics 2003:161-170.

[24] Jeannin M, Garambois S, Gregoire C, Jongmans D. Multi-configuration GPR measurements for geometrical fracture characterization in limestone cliffs (Alps). Geophysics 2006;71:B85-B92.

[25] Deparis J, Garambois S, Hantz D. On the potential of Ground Penetrating Radar to help rock fall hazard assessment of a limestone scale. Engineering Geology 2007;94:89102.

[26] Bieniawski ZT, Van Heerden WL. The significance of in situ tests on large rock specimens. Int J Rock Mech Min Sci 1975;12:101-113.

[27] Lama RD, Vutukuri VS. Handbook on Mechanical Properties of Rocks, Vol. II: Testing Techniques and Results. Switzerland: Trans Tech Publications, 1978.

[28] Scavia C. A method for the study of crack propagation in rock structures. Géotechnique 1995;45 (3):447-463.

[29] Castelli M, Scavia C. Fracture mechanics approach to the study of failure in rock. Revue européenne de génie civil 2004;8:653-682. 


\section{FIGURE CAPTIONS.}

Fig. 1. Typical failure configurations in steep limestone cliffs, with beds dipping less than $30^{\circ}(\mathrm{A}$ and $\mathrm{B})$ or more than $30^{\circ}(\mathrm{C})$

Fig. 2. Geological map of the Dauphinoise zone of the Alps: Upper Jurassic and Cretaceous sedimentary massifs (shaded), External Crystalline massifs (cross pattern).Location of the rock falls analysed: Pas du Fouillet (1), Dent du Loup (2), Ranc (3) and Goule Blanche (4)

Fig. 3. Failure criterion for a normal tensile force. $\mathrm{N}_{2}$ and $\mathrm{T}_{2}$ : normal and tangential forces. $\mathrm{c}_{\mathrm{rb}}$ and $\sigma_{\mathrm{trb}}$ : cohesion and tensile strength. $\mathrm{A}_{\mathrm{rb}}$ : rock bridge surface. $\psi$ : tensile friction angle. $\Phi$ : friction angle.

Fig. 4. Description of the forces for the isostatic sliding model. $\mathrm{W}$ : weight ; $\mathrm{N}$ and $\mathrm{T}$ : normal and tangential resisting forces

Fig. 5. (A) Scar of the Pas du Fouillet rock slide, (B) sketch of the scar with the rock bridge (white) and (C) cross-section A-A before failure

Fig. 6. Description of the forces for the hyperstatic sliding model. W: weight; $\mathrm{N}_{1}$ and $\mathrm{T}_{1}$ : normal and tangential resisting forces on the sliding plane; $\mathrm{N}_{2}$ and $\mathrm{T}_{2}$ : normal and tangential resisting forces on the opening plane $; \mathrm{R}_{2}$ : resisting force on the opening plane.

Fig. 7. (A) schematic cross-section of the Dent du Loup rock slide and (B) sketch of the scar with the rock bridges (white)

Fig. 8. (A) description of the forces for the isostatic toppling model and (B) schematic model with a rectangular equivalent rock bridge (hatched, area $\mathrm{A}_{\mathrm{rb}}{ }_{\mathrm{rb}}$ ) and the actual rock bridges (white, total area $\mathrm{A}_{\mathrm{rb}}$ )

Fig. 9. (A) Assumed distribution of the normal stress on a rock bridge (B) distribution of the normal stress assumed in the distinct element code UDEC; $F_{1}$ and $F_{2}$ are the forces calculated at the ends of the rock bridge

Fig. 10. (A) view of the scar of the Ranc rock fall, with the rock bridges in white and (B) cross-section A-A of the cliff before failure with the position of the equivalent rock bridge. $\mathrm{W}$ : weight of the unstable block; $\mathrm{H}_{\mathrm{rb}}$ : height of the equivalent rock bridge.

Fig. 11. Description of the forces for the hyperstatic toppling model. W: weight $; \mathrm{N}_{1}$ and $\mathrm{T}_{1}$ : normal and tangential resisting forces on the basal plane; $\mathrm{N}_{2}$ and $\mathrm{T}_{2}$ : normal and tangential resisting forces on the rock bridge $; \mathrm{R}_{2}$ : resultant of $\mathrm{N}_{2}$ and $\mathrm{T}_{2}$

Fig. 12. Determination of the resisting force $\mathrm{R}_{2}$ using the maximum work principle. $\mathrm{u}$ is the displacement vector.

Fig. 13. (A) Sketch of the scar of the Goule Blanche rock fall, (B) focus on the zone of the intact rock fracture and $(\mathrm{C})$ cross-section of the cliff before failure 
Table 1. Intact rock and discontinuity physical and mechanical parameters obtained from laboratory tests, number of tests $(\mathrm{N})$, average value $(\overline{\mathrm{X}})$ and standard deviation $(\Delta \mathrm{X})$

\begin{tabular}{ccc}
\hline & $\mathrm{N}$ & $\overline{\mathrm{X}} \pm \Delta \mathrm{X}$ \\
\hline Porosity $\mathrm{n}(\%)$ & 57 & $0.6 \pm 0.1$ \\
Density $\gamma$ & 57 & $2.69 \pm 0.01$ \\
Modulus of elasticity $\mathrm{E}_{50}(\mathrm{GPa})$ & 6 & $68 \pm 7$ \\
Poisson's ratio $v$ & 6 & $0.31 \pm 0.06$ \\
Indirect tensile strength $\sigma_{\mathrm{tb}}(\mathrm{MPa})$ & 19 & $7.0 \pm 3$ \\
Uniaxial compression strength $\sigma_{\mathrm{c}}(\mathrm{MPa})$ & 8 & $141 \pm 21$ \\
Cohesion of the intact rock $c(\mathrm{MPa})$ & 11 & $23 \pm 3$ \\
Friction angle of the intact rock $\phi_{\text {rock }}\left({ }^{\circ}\right)$ & 11 & $54 \pm 3$ \\
Friction angle of the discontinuities $\left(^{\circ}\right)$ & 12 & $30-43^{\circ}$ \\
\hline
\end{tabular}


Table 2. Failure configuration, failure mechanism, volume, rock bridge proportion, cohesion and tensile strength for the back-analysed rock falls (Iso.=isostatique, Hyp.=hyperstatique)

\begin{tabular}{ccccccc}
\hline Name & $\begin{array}{c}\text { Failure } \\
\text { configuration }\end{array}$ & $\begin{array}{c}\text { Failure } \\
\text { mechanism }\end{array}$ & $\begin{array}{c}\text { Volume } \\
\left(\mathrm{m}^{3}\right)\end{array}$ & $\begin{array}{c}\text { Rock } \\
\text { bridge } \\
\text { proportion }\end{array}$ & $\begin{array}{c}\text { Cohesion } \\
(\mathrm{MPa})\end{array}$ & $\begin{array}{c}\text { Tensile } \\
\text { strength (MPa) }\end{array}$ \\
\hline Vierge Vercors & $\mathrm{A}$ & Iso. sliding & 117 & 0.003 & $\mathrm{c}=4.3$ & $\sigma_{\mathrm{t}}=1.3$ \\
Chalimont & $\mathrm{A}$ & Iso. sliding & 48 & 0.002 & $\mathrm{c}=10.7$ & $\sigma_{\mathrm{t}}=3.2$ \\
Pas du Fouillet & $\mathrm{A}$ & Iso. sliding & 24 & 0.002 & $\mathrm{c}=6.6$ & $\sigma_{\mathrm{t}}=2.0$ \\
Dent du Loup & $\mathrm{C}$ & Hyp. sliding & 3500 & 0.008 & $\mathrm{c}=12.4$ & $\sigma_{\mathrm{t}}=3.8$ \\
Pas de la Balme & $\mathrm{A}$ & Hyp. sliding & 230 & 0.002 & $\mathrm{c}=9.0$ & $\sigma_{\mathrm{t}}=2.7$ \\
Les Olivets & $\mathrm{B}$ & Hyp. sliding & 90 & 0.006 & $\mathrm{c}=2.7$ & $\sigma_{\mathrm{t}}=0.8$ \\
Ranc & $\mathrm{B}$ & Iso. toppling & 2000 & 0.05 & $\mathrm{c}=10.4$ & $\sigma_{\mathrm{t}}=3.2$ \\
Roche du Midi & $\mathrm{B}$ & Iso. toppling & 282 & 0.014 & $\mathrm{c}=7.5$ & $\sigma_{\mathrm{t}}=2.2$ \\
Goule Blanche & $\mathrm{B}$ & Hyp. toppling & 30 & 0.008 & $\mathrm{c}=14.0$ & $\sigma_{\mathrm{t}}=4.2$ \\
\hline \multicolumn{7}{c}{ Laboratory tests } \\
\hline
\end{tabular}


Figure 1
Click here to download high resolution image

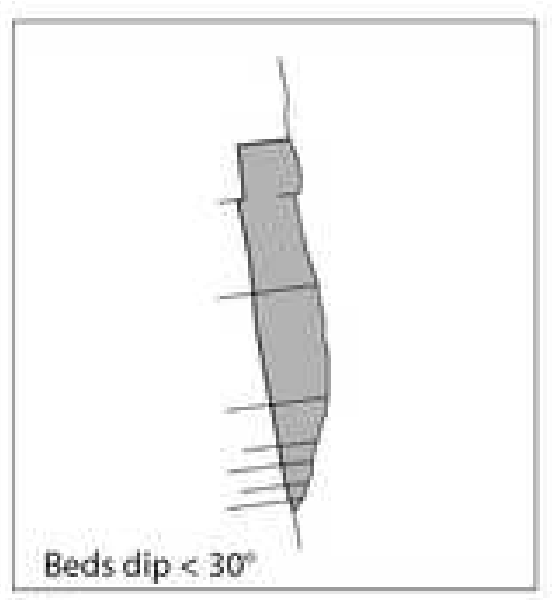

(A)

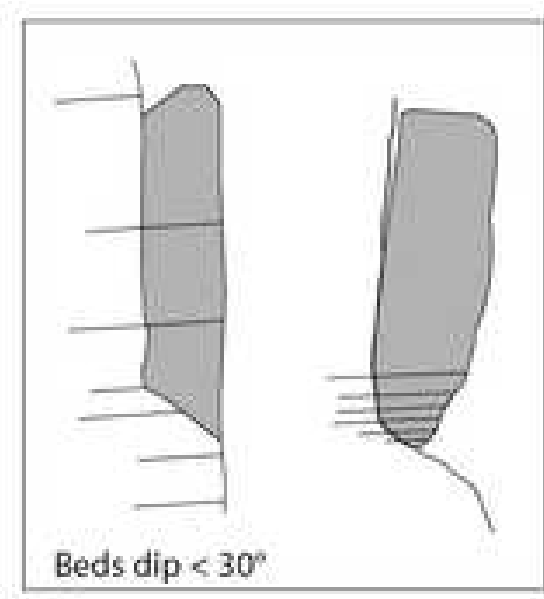

(B)

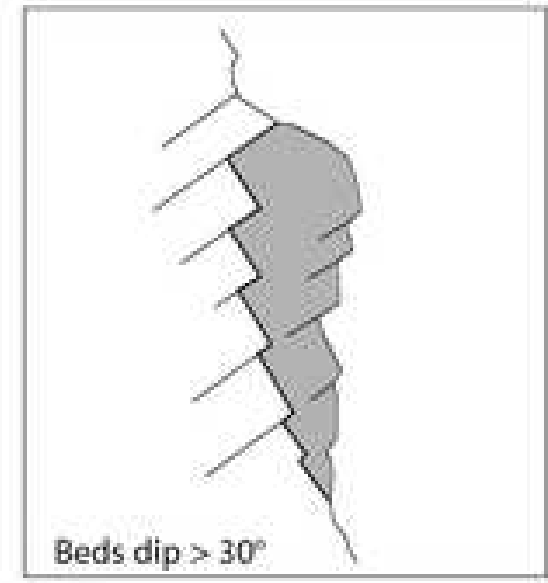

(C) 
Click here to download high resolution image

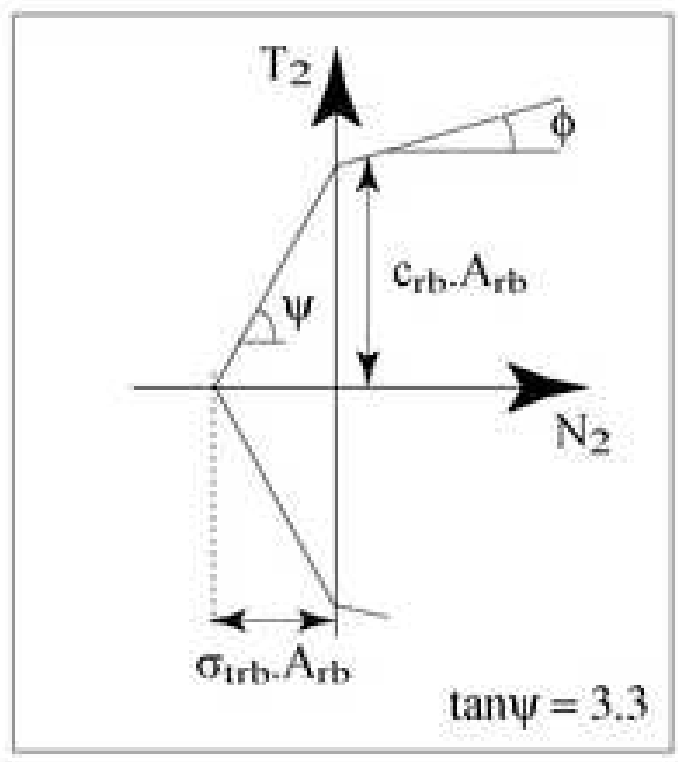


Figure 4
Click here to download high resolution image

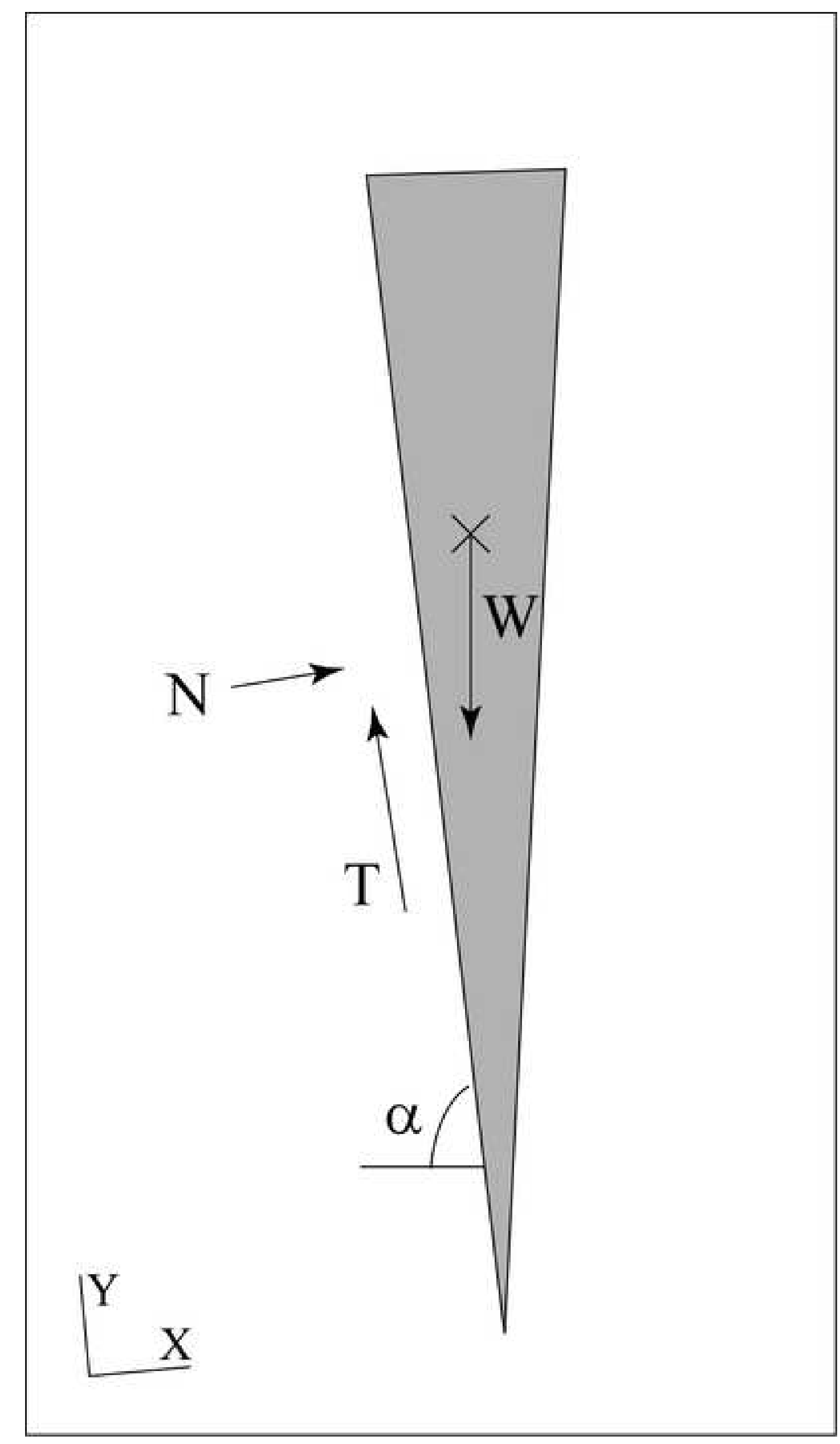


Click here to download high resolution image

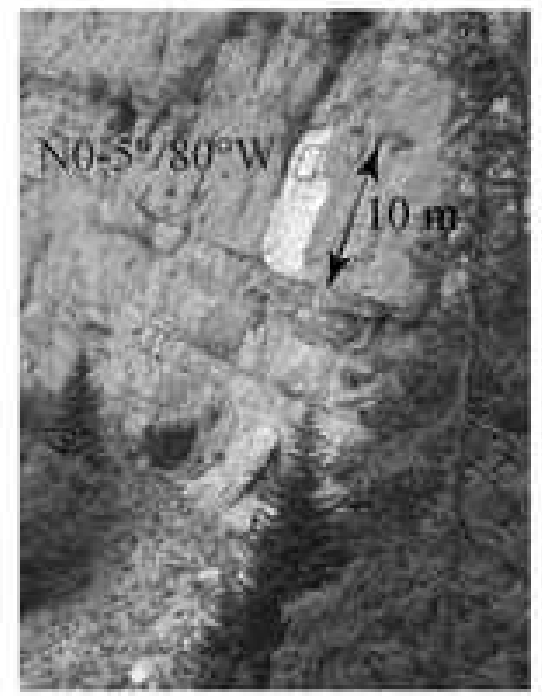

(A)

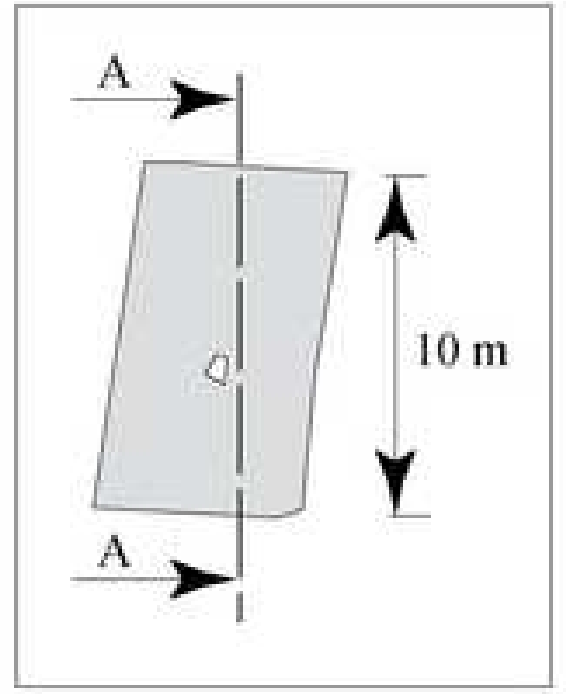

(B)

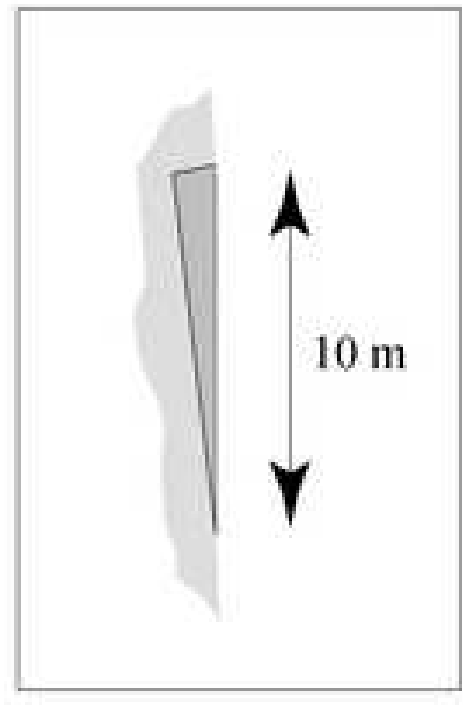

(C) 
Figure 6

Click here to download high resolution image

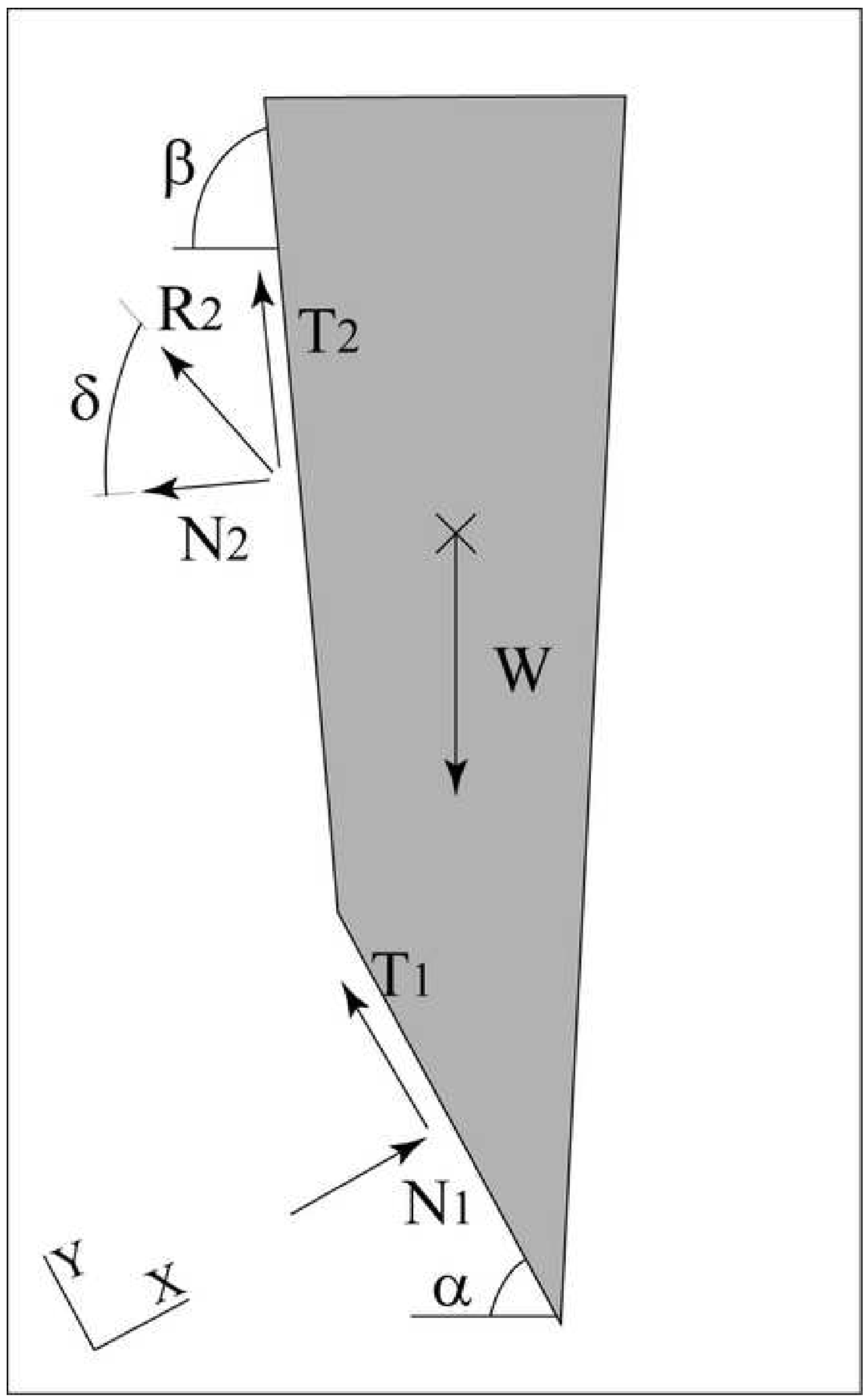




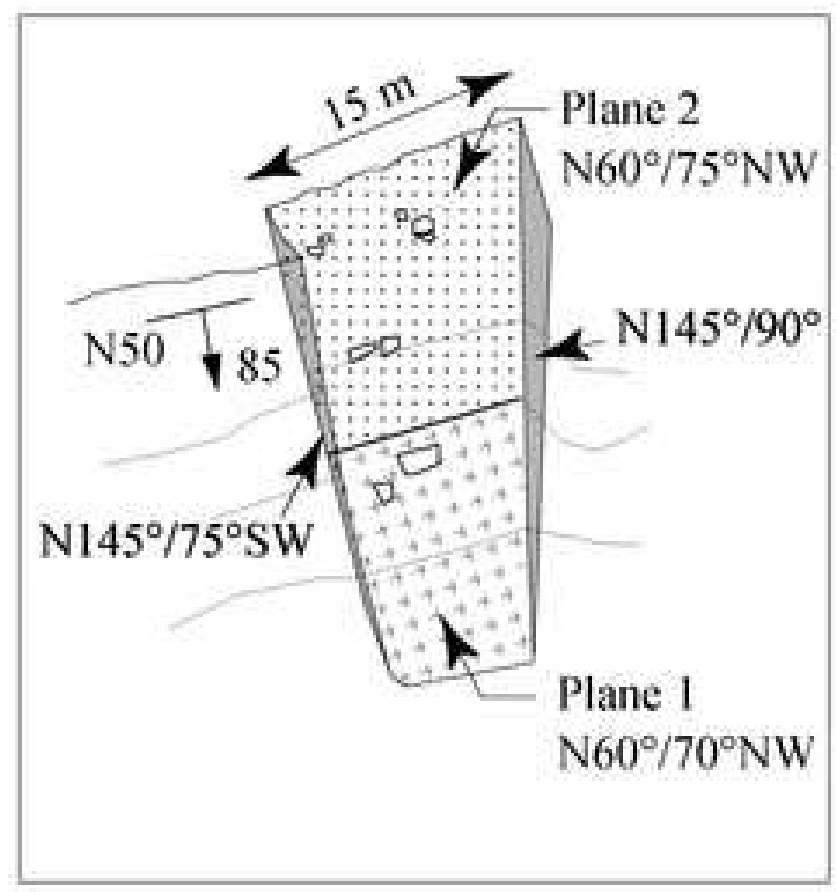

(B)
Figure 7
Click here to download high resolution image
(A)

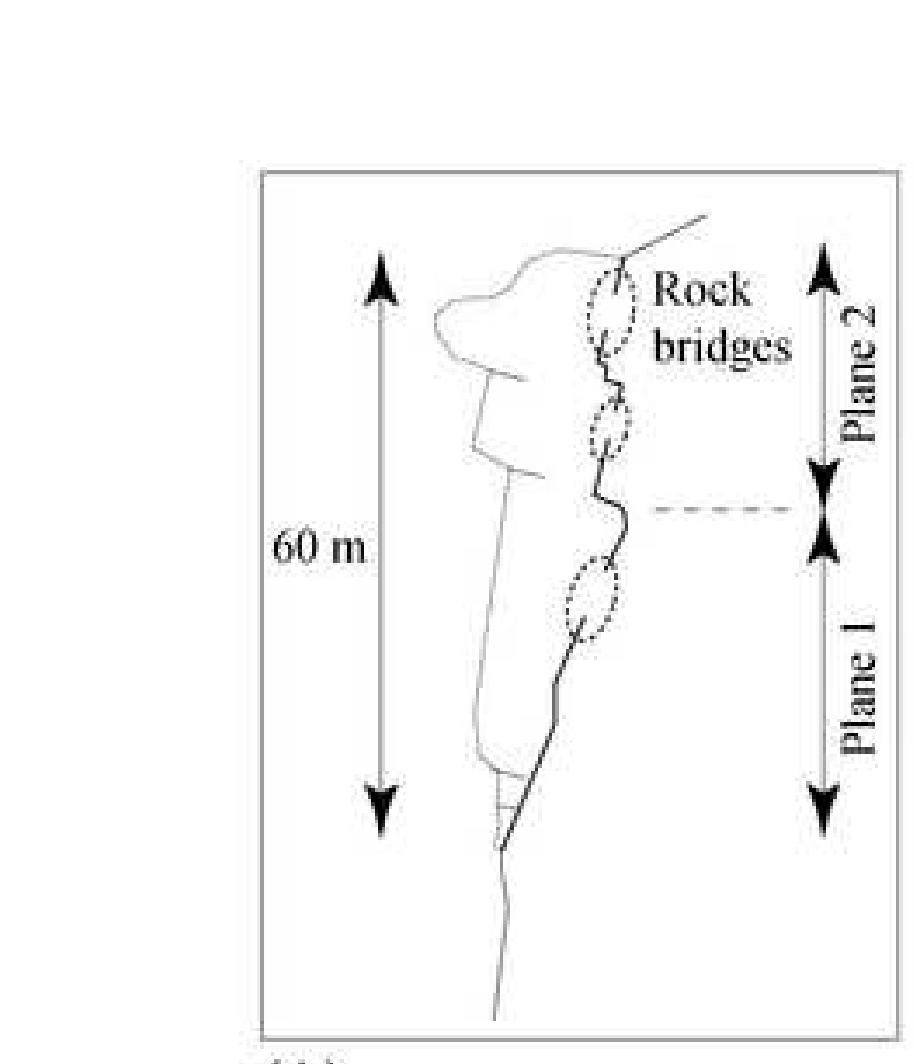

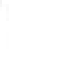




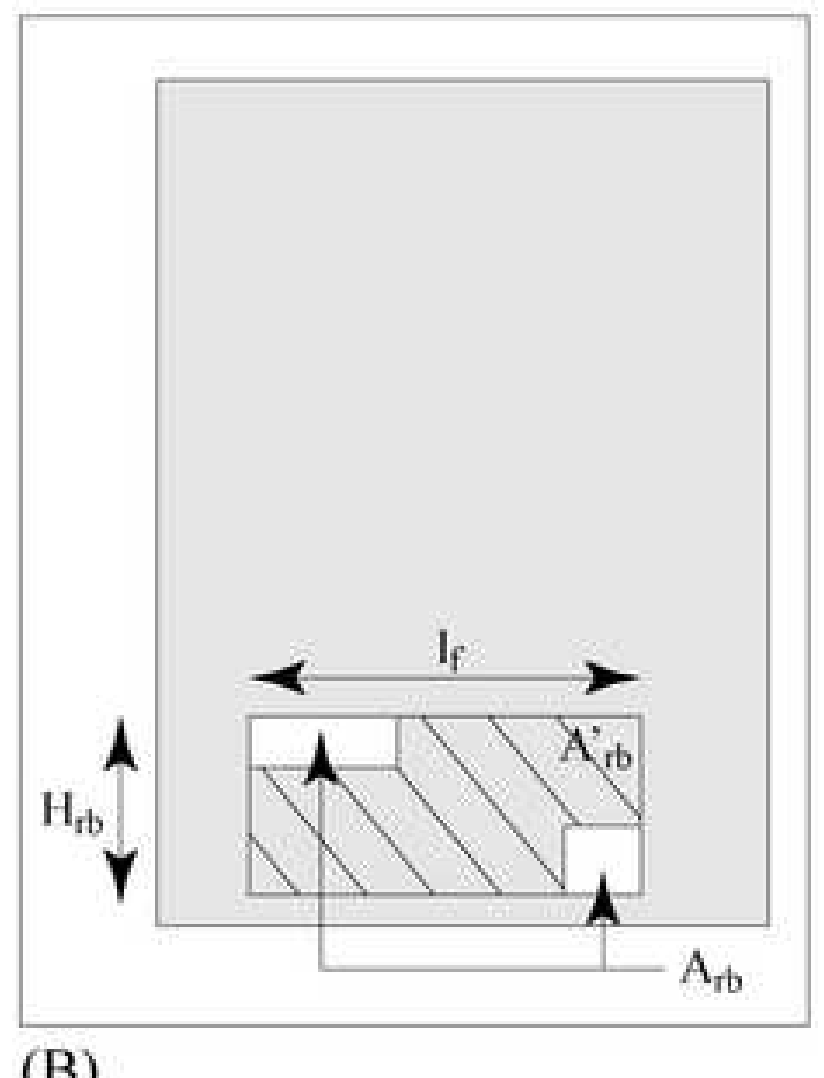

(B)

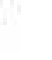

Figure 8
Click here to download high resolution image
(A)

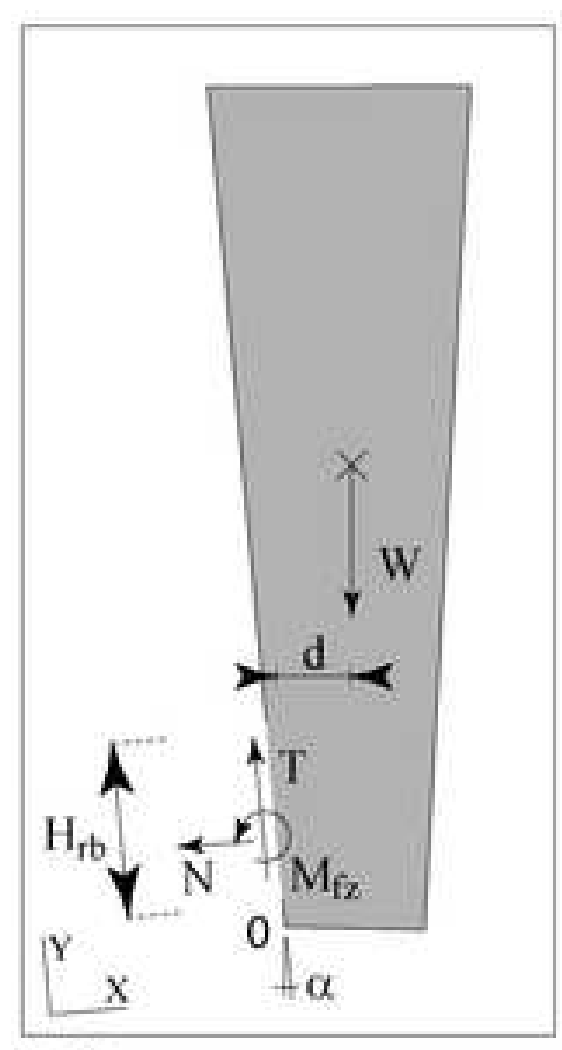


Figure 9
Click here to download high resolution image

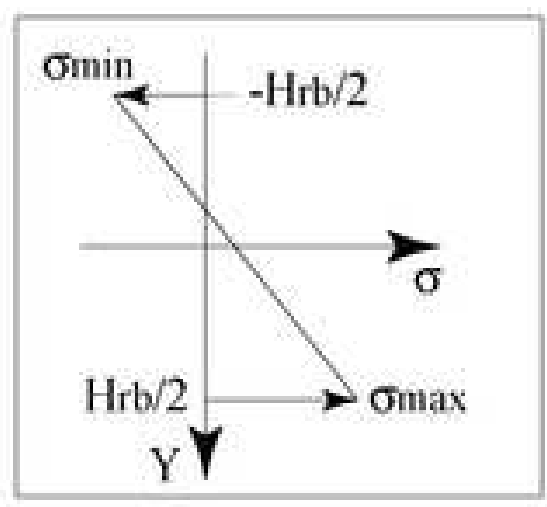

(A)

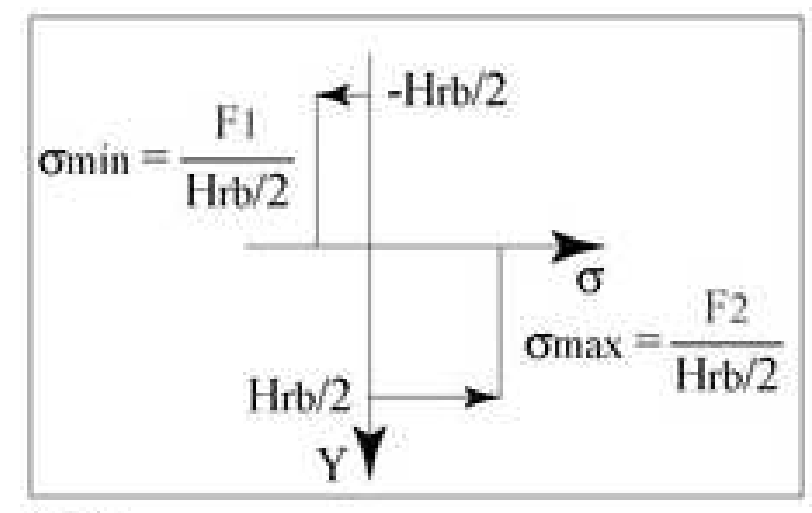

(B) 


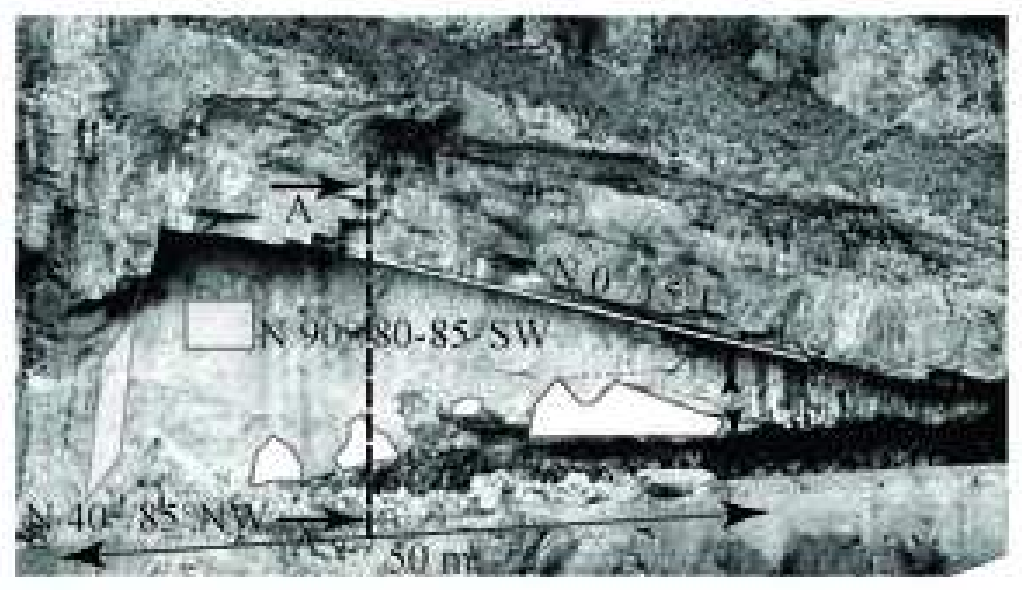

(A)

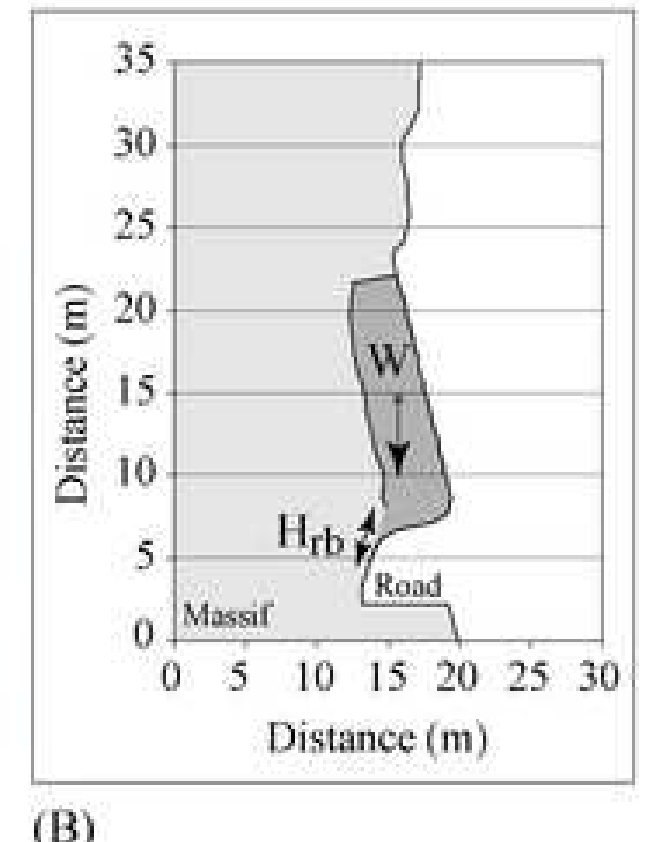

(B)

)

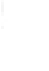


Figure11
Click her

Click here to download high resolution image

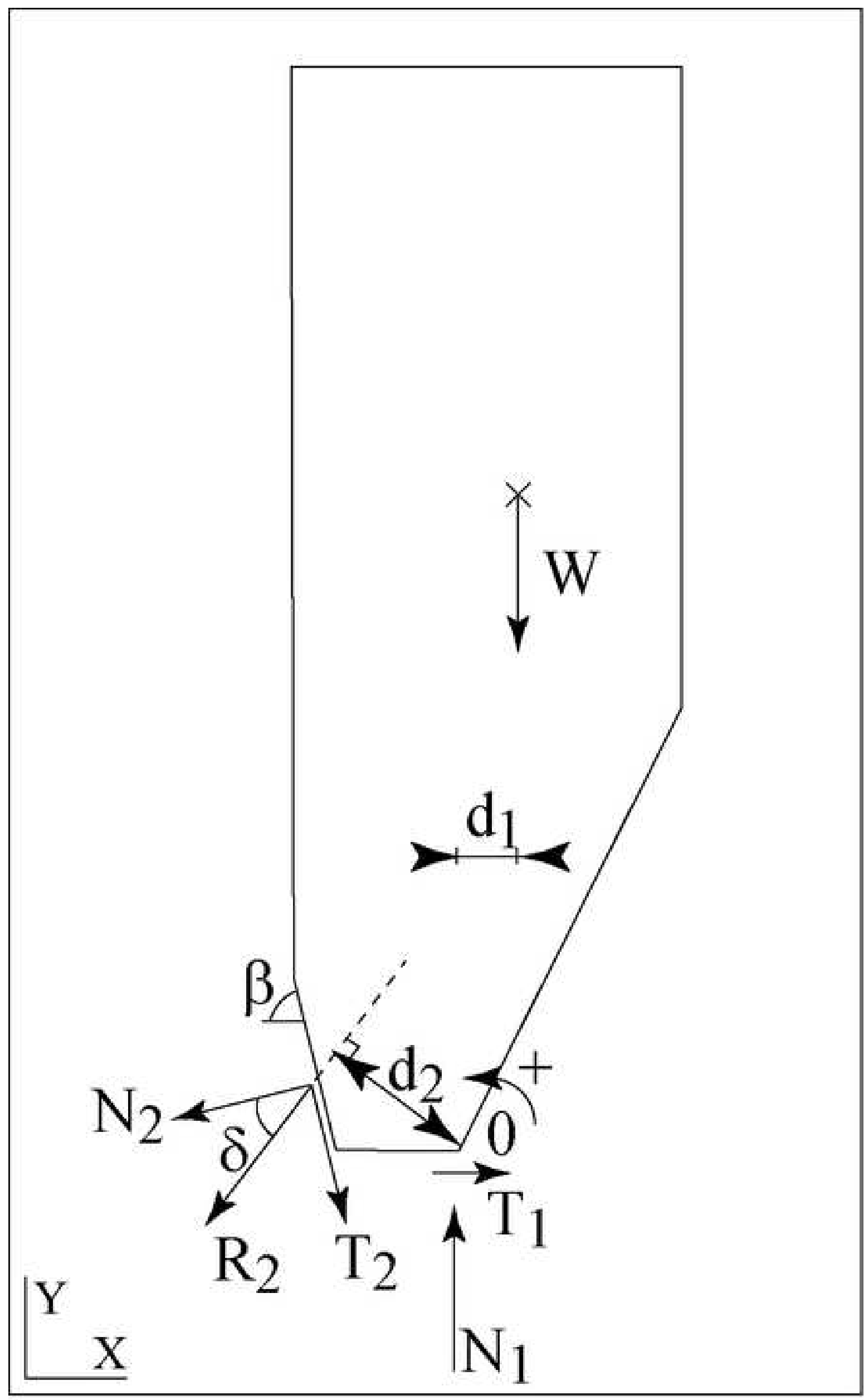




\section{Figure 1}

Click here to download high resolution image

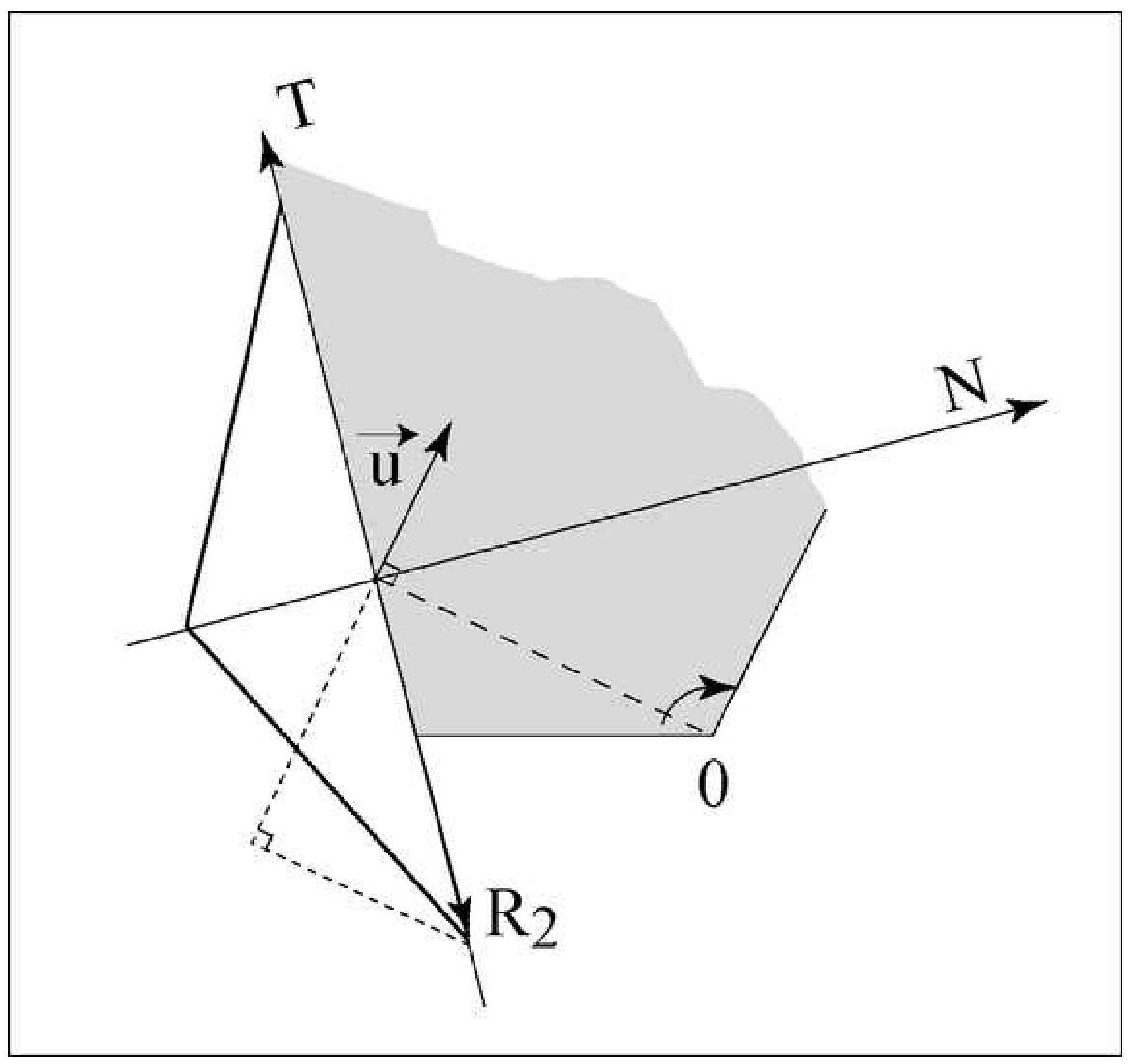


Figure 13
Click here to download high resolution image
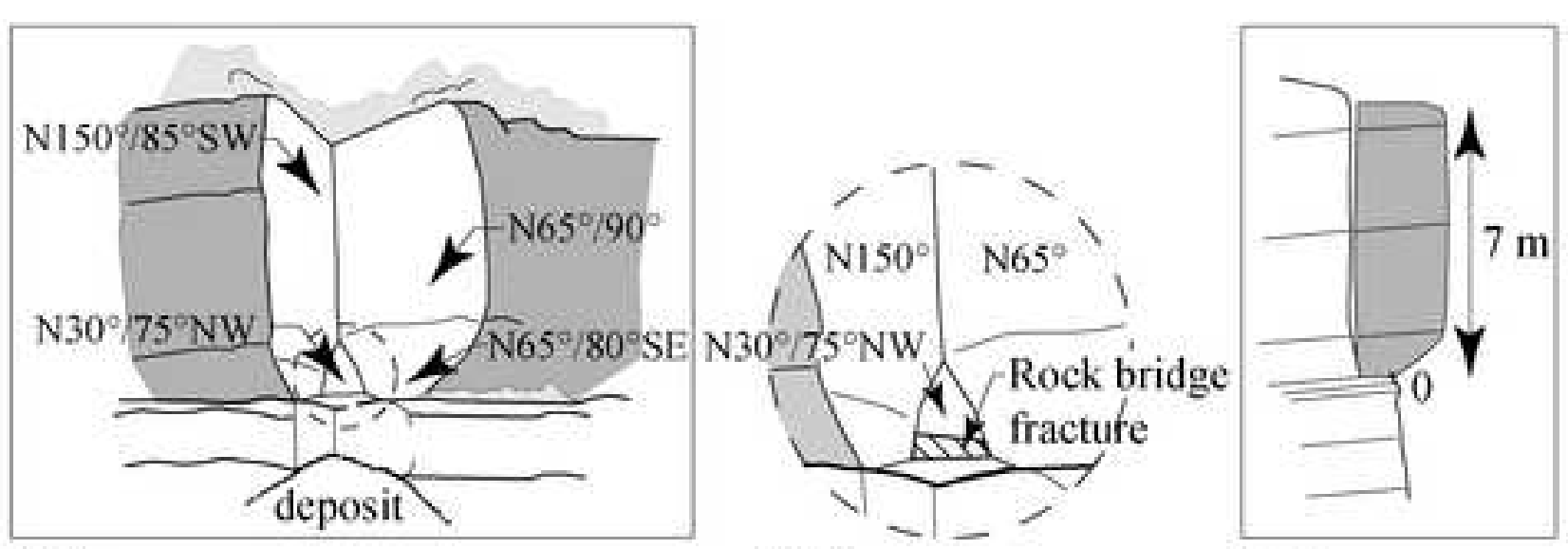

(B)

(A)
(C) 